\title{
Consumer Satisfaction of Texture Modified Meals Served in Residential Aged-Care Facilities
}

\author{
Anna Miles ${ }^{1 *}$, Kaye Dennison ${ }^{2}$, Monica Amer Oad ${ }^{3}$, Lara Shasha $^{3}$, Maia Royal ${ }^{4}$ \\ ${ }^{1}$ Senior Lecturer, Speech Science, The University of Auckland, Auckland, New Zealand \\ ${ }^{2}$ Dietitian, Optimize Health Solutions Ltd, Auckland, New Zealand \\ ${ }^{3}$ Research Assistant, Speech Science, The University of Auckland, Auckland, New Zealand \\ ${ }^{4}$ Director, The Pure Food Co, Auckland, New Zealand
}

\begin{abstract}
Food service plays an important role in optimising residential aged care facilities (RACFs) residents' health with mealtime satisfaction a critical component. One third of residents consume texture-modified diets (TMDs). This study investigated satisfaction of TMDs in RACFs collecting documentation audit and interviews with residents and their carers at 12 RACFs. Eating Assessment Tool (EAT-10) and Mini Nutritional Assessment (MNA-SF®) were completed. Inclusion criteria was residents receiving commercially prepared nutrient-fortified TMD meals. 67 residents (aged 68-99yrs) were audited and 39 were interviewed. $97 \%$ of residents had documented cognitive impairment. 84\% had elevated EAT-10 and $97 \%$ were at risk of malnutrition on MNA-SF®. The majority (>80\%) of residents were satisfied with the flavour of their meals. Residents in RACFs receiving TMDs have complex medical issues, dysphagia and malnutrition risk. Yet, two thirds of residents were able to offer suggestions for mealtime improvements. Food services should not discount their contributions in menu planning.
\end{abstract}

Keywords: Aged care; Dysphagia, Fortified foods, Malnutrition, Nutrition, Texture modified diets.

\section{Introduction}

Dysphagia and malnutrition are acknowledged risks to health and wellbeing in older adults and are common in those in residential aged care facilities (RACFs) [1]. A systematic review and metaanalysis found $28 \%$ of RACF residents were malnourished and a further $49 \%$ were at risk of malnutrition [2]. Mealtime difficulties are common in RACF residents with dysphagia risk higher in those in hospital-level compared to rest home-level care [1]. Swallowing difficulties extend beyond the physical symptoms of dysphagia including impact of dentition, physical, cognitive and visual impairment on mealtimes.

The relationship between malnutrition and dysphagia is complex. Malnourished older people are at greater risk of dysphagia due to reduced muscle function, structure and metabolism [3]. In turn, difficulties swallowing inherently lead to difficulties consuming adequate nutrition with a reduction in safe food choices as well as speed and efficiency of eating.
Malnutrition risk is particularly high for people with dysphagia who require texture modified diets (TMDs) [4-6]. Pureed diets often provide fewer calories than their standard diet counterparts, due to the need to add liquid during the production process, thus diluting nutrients.

Corresponding Author: Anna Miles, Senior Lecturer, Speech Science, The University of Auckland, Auckland, New Zealand Received date: June 06, 2019; Accepted date: June 13, 2019; Published date: June 14, 2019.

DOI: https://doi.org/10.31546/IJFSNR.1005 
In a recent New Zealand study, data from 35,469 residents reported one third of residents were on TMDs [10]. Mealtime observations and meal / menu audits found only half of residents ate full meals and many protein and carbohydrate servings did not comply with national nutritional standards [7]. Commercially prepared texture modified, nutrient fortified (TMNF) meals are gaining in availability and have a place in supporting this vulnerable population [4-5,8-9]. A recent systematic review concluded that consuming energy and protein enrichment of regular meals can significantly increase energy and protein intake. The authors concluded that fortification was well tolerated and cost effective for hospitalised older people [10]. For food services, who are managing a multitude of dietary needs, commercial products can be easy and outsourcing can avoid the need for specialist equipment and a skilled workforce for TMD production.

It is widely observed that pureed diets lack sensory or taste appeal and can lead to food refusal and reduced intake $[4,6]$. Consumer satisfaction studies in RACFs are limited, perhaps due to the complexities of working with older people with medical, physical, cognitive and communication difficulties. Yet, it is established that even the preferences of age-matched older adults differ from those of older adults consuming a TMD [11]. This study investigated consumer satisfaction and health status of residents consuming commercially prepared TMNF meals in New Zealand. The study asked: What are the health demographics of residents consuming commercially prepared TMNF meals in New Zealand? Are residents consuming commercially prepared TMNF meals satisfied with their meals? Do residents consuming commercially prepared TMNF meals have suggestions for improvements?

\section{Methods}

This project gained national ethics approval (UAHPEC020683) and individual RACF managers provided written institution consent. This prospective observational quantitative study was designed and recorded according to the STROBE statement for observational studies [12].

Currently, there is only one provider of commercially prepared TMNF meals in New Zealand. Foods are fortified with plantbased protein, oils and fibre. Thirteen RACFs based in the upper North Island, who received commercially prepared TMNF meals, from this provider, were invited via email to participate. Portion sizes are 100 gram servings of savoury, vegetable and dessert items which can be combined to develop meals or eaten as snacks. Based on the range of commercially prepared TMNF menu items currently available, residents can potentially consume up to 10 servings per day i.e. a hot meal may be com- -prised of 1 meat, 1 carbohydrate, 1 vegetable, 1 dessert.

Clinical notes of all residents consuming $>3$ servings of commercially prepared TMNF foods per day at all consenting facilities were reviewed. Collected data included: demographic and medical information, documented choking, falls and pressure injury risk, duration of consumption of commercially prepared TMNF foods, and current weight (within 1-month). All residents consuming $>3$ servings of commercially prepared TMNF foods per day were invited to participate in an interview. All residents provided written consent for interviews and where cognitive or communication impairments were documented, nextof-kin written consent was also gained. Residents with cognitive or communication impairments were not excluded in order to represent the true demographic of RACF residents consuming TMNFs. Two qualified speech-language pathologists, experienced in communicating with adults with communication difficulties, administered structured interviews. Interviews gained feedback on satisfaction of commercially prepared TMNF meals as well as inhouse foods consumed throughout the day (breakfast, lunch, dinner, soup and snacks). Suggestions for future TMD meals and snack development were encouraged. Residents were asked to quantify their satisfaction with each meal on a scale of $1-10(1=$ not at all; $10=$ excellent). They were asked to agree or disagree to the following statements: i) the colour of meals makes them look appealing, ii) the flavour of meals is good, iii) the aroma/smell of meals is appealing, iv) the presentation of meals is attractive, v) the variety of meals available is good. Dysphagia risk was determined using the Eating Assessment Tool (EAT10) [13] and nutrition risk was assessed using the Mini Nutritional Assessment-Short Form (MNA-SF®) [2].

Responses to closed and Likert scale interview questions, the EAT-10 and MNA-SF® and clinical notes data (demographic, swallowing and nutrition risk factors) were analysed using descriptive statistics and graphing. Responses to open ended questions 'what is the most important thing about the food you eat?' and 'what food gives you most pleasure?' were categorised and tallied. In order to explore differences in those with prolonged use of commercially prepared TMNF foods, the cohort was categorised as $<8$ weeks versus $8+$ weeks. 
Correlations between variables were explored using Spearman's correlations, Chi-squared test and point biserial correlations using IBM SPSS Statistics Data Editor (Version 23, IBM Corporation, Chicago, Ill).

\section{Results}

12 out of 13 invited RACFs consented to the study. Resident demographic information of all 67 residents consuming commercially prepared TMNF meals at the 12 consenting RACFs is displayed in Table 1. Regular weights were not available in all clinical notes, with 30 residents weighed within the last week, 29 last weighed 7-31 days, 2 last weighted between 1-3 months ago, 2 last weighed between 4-6 months ago, and 4 without a recorded weight in the last 12 months.

Residents consumed between 3-10 serves of commercially prepared TMNF food per day (Table 2). While number of por-tions of commercially prepared TMNFs did not correlate with other variables, number of weeks on commercially prepared TMNF foods was significantly correlated with increased age (Rs $=.30, \mathrm{p}<.05)$, lower body mass index $(\mathrm{BMI})(\mathrm{Rs}=-.35, \mathrm{p}<.05)$, lower current weight $(\mathrm{Rs}=-.27, \mathrm{p}<.05)$, and increased use of supplements (Rs $=-.46, \mathrm{p}<001)$. Residents taking 8+ weeks of commercially prepared TMNF foods were significantly more likely to be on supplements $(\mathrm{X} 2=14.74, \mathrm{p}<.001)$.
39 residents consented to interview; 8 independently, and 31 with the support of a carer and family member. All residents, with communication support, were able to communicate responses to the EAT-10 and rating scale questions (either verbally or non-verbally). 32 out of 39 interviewed residents $(82 \%)$ were able to offer an opinion on their mealtime preferences with the support of a carer / family member. Figure 1 displays interviewed residents' EAT-10 and MNA-SF® scores (weight within 1-month was not available for 8 of the interviewed residents). 97\% of residents $(n=30 / 31)$ were identified as at risk of malnutrition or malnourished (35\%, 11/31 malnourished) and $84 \%$ of residents $(n=32 / 39)$ were identified as outside of normal range for swallowing difficulties ( $>3$ on EAT10). EAT-10 scores were negatively correlated with MNA-SF® scores (Rs $=-.50, \mathrm{p}<.01)$ and with documented choking risk (Rs $=-.50, \mathrm{p}<001)$. Elevated MNA-SF® scores were correlated with lower BMI (Rs $=.40, \mathrm{p}<.05)$ and greater total number of medical conditions $(\mathrm{Rs}=.37, \mathrm{p}<05)$. EAT-10 and MNA-SF® did not correlate with number of weeks on commercially prepared TMNF foods (<8 vs $8+$ wks, $\mathrm{p}>.05)$

Table 1: Demographic information of residents $(n=67)$

\begin{tabular}{|c|c|c|c|}
\hline \multicolumn{2}{|l|}{ Demographics } & Data (n) & $\%$ \\
\hline \multicolumn{2}{|l|}{ Mean age (range), SD } & \multicolumn{2}{|c|}{$85 y(68-99), 7.7 y$} \\
\hline \multicolumn{2}{|l|}{ Gender (male) } & 21 & 31 \\
\hline \multirow[t]{6}{*}{ Ethnicity } & NZ European & 47 & 70 \\
\hline & NZ Māori & 0 & 0 \\
\hline & European & 13 & 19 \\
\hline & Asia & 2 & 3 \\
\hline & Pacific Island & 2 & 3 \\
\hline & Other & 3 & 4 \\
\hline \multirow[t]{3}{*}{ Level of Care } & Hospital & 52 & 78 \\
\hline & Rest home & 11 & 16 \\
\hline & Dementia Unit & 4 & 6 \\
\hline \multirow{4}{*}{$\begin{array}{lr}\text { 'At risk' } & \text { for } \\
\text { dysphagia aetiologies } \\
\text { documented } \\
\text { clinical notes }\end{array}$} & Dementia (Alzheimer's, vascular, other) & 37 & 55 \\
\hline & $\begin{array}{l}\begin{array}{l}\text { Documented cognitive impairment } \\
\text { (memory loss, wandering, confusion) }\end{array} \\
\end{array}$ & 65 & 97 \\
\hline & $\begin{array}{l}\text { Acquired brain injury (stroke, traumatic } \\
\text { brain injury, tumour) }\end{array}$ & 25 & 37 \\
\hline & Progressive neurological disease & 9 & 13 \\
\hline \multicolumn{2}{|c|}{$\begin{array}{l}\text { Number of medical diagnoses per resident documented in clinical } \\
\text { notes. Mean (range), SD }\end{array}$} & \multicolumn{2}{|c|}{8.06 (range $1-16$ ), 3.16} \\
\hline \multirow{2}{*}{\multicolumn{2}{|c|}{$\begin{array}{l}\text { Number of regular medicines per resident documented in clinical } \\
\text { notes. Mean (range), SD }\end{array}$}} & \multicolumn{2}{|c|}{$6.46(2-13), 2.82$} \\
\hline & & \multicolumn{2}{|c|}{$49(73 \%) 5+$ medicines } \\
\hline
\end{tabular}


Anna Miles et al.

\begin{tabular}{|c|c|c|c|}
\hline \multirow[t]{2}{*}{ Pressure injury } & Documented pressure injury risk & 55 & 82 \\
\hline & Documented history of pressure injury & 21 & 31 \\
\hline \multirow[t]{4}{*}{ Mobility } & Independent & 3 & 4 \\
\hline & Stick / walker & 22 & 33 \\
\hline & Wheelchair & 11 & 16 \\
\hline & Bed / chair bound & 29 & 43 \\
\hline \multicolumn{2}{|c|}{ Falls risk documented in clinical notes } & 66 & 99 \\
\hline \multicolumn{2}{|c|}{ Osteoporosis documented in clinical notes } & 21 & 31 \\
\hline \multirow[t]{2}{*}{ BMI $(n=41)$} & \multicolumn{3}{|l|}{ Mean BMI 23 (range 13-35), SD 5.22} \\
\hline & Underweight & \multicolumn{2}{|c|}{$\begin{array}{l}9 \text { (BMI range 12.64- } \\
18.4)\end{array}$} \\
\hline \multirow{2}{*}{$\begin{array}{l}\text { N.B. } 26 \text { did not have a } \\
\text { documented } \\
\text { preventing } \\
\text { calculation }\end{array}$} & Healthy weight & \multicolumn{2}{|c|}{$\begin{array}{l}10 \text { (BMI range 18.5- } \\
24.80)\end{array}$} \\
\hline & Overweight & \multicolumn{2}{|c|}{12 (BMI range 25-34.52) } \\
\hline
\end{tabular}

$S D$ - standard deviation; BMI - body mass index

Table 2: Nutrition and swallowing information for audited residents

\begin{tabular}{|l|l|l|l|}
\hline Demographic n= 67 & Data & \% \\
\hline \multirow{4}{*}{ Food Level (IDDSI 3-7) } & 3 Liquidised & 0 & 0 \\
\cline { 2 - 4 } & 4 Pureed & 48 & 72 \\
\cline { 2 - 4 } & 5 Minced \& Moist & 2 & 3 \\
\cline { 2 - 4 } & 6 Soft \& bite sized & 15 & 22 \\
\cline { 2 - 4 } & 7 Regular & 0 & 0 \\
\hline \multirow{4}{*}{ Drink Level (IDDSI 0-4) } & 0 Thin & 41 & 62 \\
\cline { 2 - 4 } & 1 Slightly thick & 0 & 0 \\
\cline { 2 - 4 } & 2 Mildly thick & 21 & 31 \\
\cline { 2 - 4 } & 3 Moderately Thick & 3 & 4 \\
\cline { 2 - 4 } & 4 Extremely Thick & 0 & 0 \\
\hline \multirow{4}{*}{$\begin{array}{l}\text { Number of commercially } \\
\text { portions (100g) consumed per day }\end{array}$} & Median 7, range 3-10, IQR 2 \\
\hline Duration on commercially prepared TMNF meals & Mean 18 weeks, range 2-100, SD 26 \\
\hline Supplements & 27 & 40 \\
\hline Assistance with meals & Own teeth & 47 & 70 \\
\hline Documented risk of choking & Dentures & 47 & 70 \\
\hline Dentition & Edentulous & 8 & 28 \\
\cline { 2 - 4 } & & 60 \\
\hline
\end{tabular}


Table 3: What food gives you most pleasure?

\begin{tabular}{|c|c|c|c|}
\hline Question & Category & Illustrative responses & $\#$ \\
\hline \multirow[t]{9}{*}{$\begin{array}{l}\text { What food gives you } \\
\text { most pleasure? }\end{array}$} & Sweet & $\begin{array}{l}\text { Ice-cream, puddings, pavlova, } \\
\text { sweets, yoghurt, Milo }\end{array}$ & 15 \\
\hline & Culturally appropriate & Having family around, Korean food & 2 \\
\hline & Easy texture, no lumps & $\begin{array}{l}\text { Soft enough } \\
\text { Soups } \\
\text { Scrambled eggs } \\
\text { The soups are too thin so I don't } \\
\text { have them as they make me choke } \\
\text { no lumps . I gag }\end{array}$ & 8 \\
\hline & Tasty food & Tasty food & 4 \\
\hline & Hot & $\begin{array}{l}\text { Hot I don't like it cold, too cold } \\
\text { hurts my mouth }\end{array}$ & 7 \\
\hline & Cold & & 2 \\
\hline & Salty & & 1 \\
\hline & Not too much & & 2 \\
\hline & Filling & & 2 \\
\hline \multirow{3}{*}{$\begin{array}{l}\text { What would help you } \\
\text { increase enjoyment? }\end{array}$} & \multicolumn{2}{|l|}{ Easy to eat } & 18 \\
\hline & \multicolumn{2}{|l|}{ Assistance } & 2 \\
\hline & \multicolumn{2}{|l|}{ Eating socially } & 10 \\
\hline Meal & $\begin{array}{l}\text { Illustrative examples of } \\
\text { favourites }\end{array}$ & \multicolumn{2}{|c|}{$\begin{array}{l}\text { Illustrative examples residents would like } \\
\text { removed from the menu }\end{array}$} \\
\hline Breakfast & $\begin{array}{l}\text { Porridge } \\
\text { Fruit puree }\end{array}$ & \multicolumn{2}{|c|}{-} \\
\hline Main meal & $\begin{array}{l}\text { Chicken } \\
\text { Fish } \\
\text { Mince } \\
\text { Carrots } \\
\text { Pumpkin } \\
\text { Scrambled eggs } \\
\text { Casseroles } \\
\text { Scalloped potatoes } \\
\text { Gravy }\end{array}$ & \multicolumn{2}{|c|}{$\begin{array}{l}\text { Pureed fish } \\
\text { All looks the same } \\
\text { Lunch and dinner are the same - I would } \\
\text { like more choice }\end{array}$} \\
\hline Soup & $\begin{array}{l}\text { Pumpkin (without spices) } \\
\text { Chicken } \\
\text { Thick tomato } \\
\text { Vegetable } \\
\text { Not sure which one but } \\
\text { it's a white colour } \\
\text { Unable to tell } \\
\text { Leek } \\
\text { Carrot }\end{array}$ & \multicolumn{2}{|c|}{$\begin{array}{l}\text { Hard to tell what they are } \\
\text { Some too thin \& so I cannot have them due } \\
\text { to choking } \\
\text { Not sure maybe mushroom soup - chocolate } \\
\text { colour } \\
\text { Ones with threads \& lumps } \\
\text { Carrot \& ginger - too intense }\end{array}$} \\
\hline
\end{tabular}




\begin{tabular}{|c|c|c|}
\hline Pudding & $\begin{array}{l}\text { Ice cream } \\
\text { Sticky date pudding } \\
\text { I used to like Bread and } \\
\text { butter pudding but they } \\
\text { don't have that here } \\
\text { Apple stew } \\
\text { Banana } \\
\text { Jelly } \\
\text { Yoghurt } \\
\text { Custard } \\
\text { Cheesecake } \\
\text { Trifle } \\
\text { Chocolate pudding } \\
\text { Mousse } \\
\text { Apple crumble / pie } \\
\text { Rice puddings }\end{array}$ & $\begin{array}{l}\text { Limited choice } \\
\text { Lumpy custard } \\
\text { Hard to tell what they are }\end{array}$ \\
\hline $\begin{array}{l}\text { Morning / afternoon } \\
\text { tea }\end{array}$ & $\begin{array}{l}\text { Cake / ice cream } \\
\text { Fortisip } \\
\text { Milo } \\
\text { Puree fortified pudding } \\
\text { Smoothies }- \text { peach \& } \\
\text { banana } \\
\text { Egg sandwich } \\
\text { Asparagus roll }\end{array}$ & $\begin{array}{l}\text { Miss Korean food } \\
\text { Limited choice }\end{array}$ \\
\hline General & \multicolumn{2}{|c|}{$\begin{array}{l}\text { 'Eating at the same table as others to make meals a social occasion. } \\
\text { 'Mum is a very social person and loves sitting with other people' } \\
\text { 'I prefer sweet stuff' } \\
\text { 'All the food looks the same' } \\
\text { "Without a menu I don't know what I'm eating' } \\
\text { 'I like choice' } \\
\text { 'I can't smell so I like to see bright colours' } \\
\text { 'It would be easier if I sorted out my teeth' }\end{array}$} \\
\hline
\end{tabular}

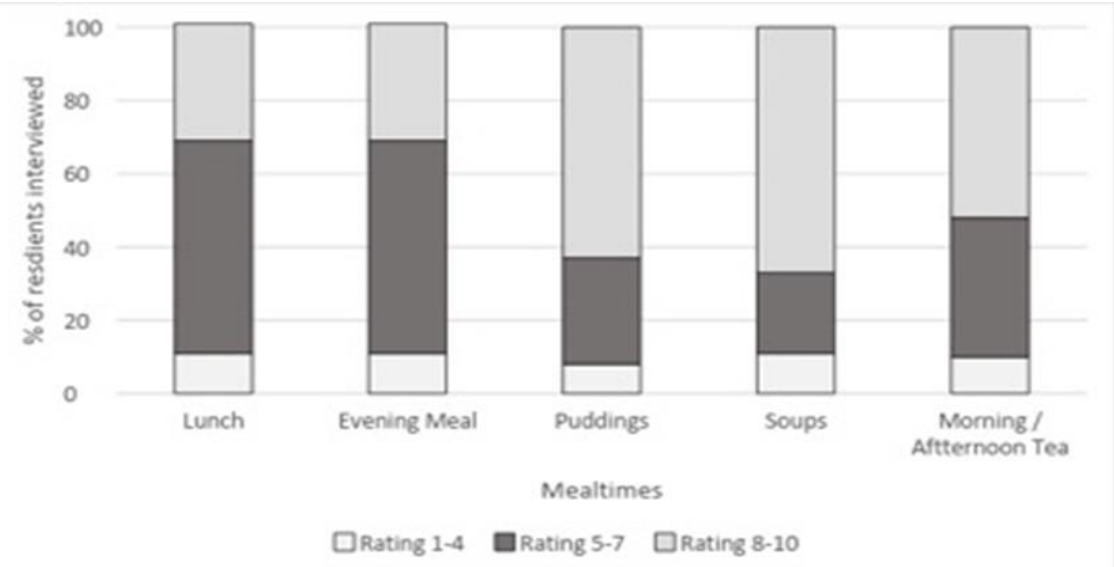

Figure 1 : Ratings given to meals by interviewed residents ( $1=$ not at all satisfied; $10=$ very satisfied $)$. 

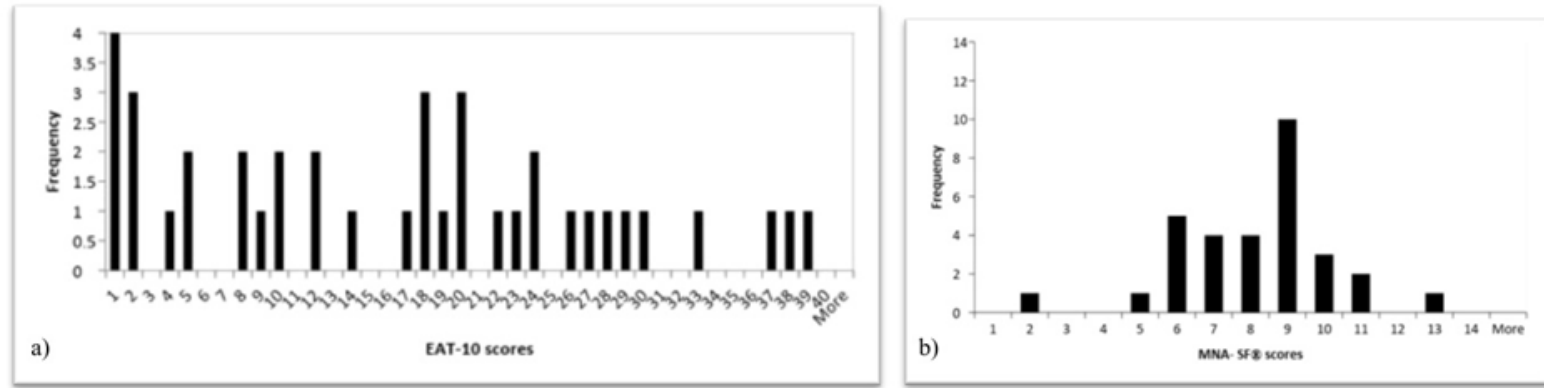

Figure 2: a) EAT-10 ( $n=39)$ scores for residents interviewed ( $>3=$ outside of normal range); b) MNA-SF® scores (n: 31$)$ for residents interviewed $(0-7=$ malnourished, $8-11=$ at risk of malnutrition, $12-14=$ normal nutritional status $)$.

Table 3 displays the categorised open responses from residents to the question 'what is the most important thing about the food you eat?' $80 \%$ of interviewees agreed to the statement 'the colour of meals is appealing', $90 \%$ to 'the flavour of meals is good', $57 \%$ the smell of meals is appealing', $63 \%$ 'the presentation of meals is attractive' and $63 \%$ 'the variety of meals available is good'. Figure 2 display resident ratings to meals.

\section{Discussion}

To our knowledge, this study provides the first exploration of mealtime satisfaction in RACFs in New Zealand. Most residents were $>85 \mathrm{yrs}$, with the majority requiring hospital-level care and with some degree of cognitive impairment. Uniquely, this study gives a voice to a high-risk group who have dysphagia, associated nutritional challenges and are receiving TMNFs $[4,8,11]$. The $>80 \mathrm{yr}$ old population is growing rapidly and has increased risk of dysphagia, malnutrition, multi-morbidity and disability $[1,14,15]$. The nutritional needs for older people is higher for some nutrients e.g. protein and calcium [16]. More research attention is required in this area given that current nutrition guidelines are based on the needs of younger adults [14].

This cohort upholds the established strong association between dysphagia and malnutrition [17]. MNA-SF® results found all but one interviewee malnourished or at risk of malnutrition. While the MNA-SF® is validated for use within this population, all residents with reported dementia and immobility are automatically identified as 'at risk of malnutrition'. The inclusion of functional, psychological and cognitive measures in the MNA-SF® are important when identifying malnutrition risk in older people living in long-term RACFs [18]. However, this inherently leads to high malnutrition risk ratings.

Increased number of weeks on TMNF was significantly associated with increased age, lower BMI and supplement use. It is reassuring that facilities are appropriately prescribing TMNF meals to these high-risk residents.
Provision of fortified meals supports the 'food first' focus to the treatment of malnutrition [19]. However, this data suggests that residents continued to be at risk of malnutrition (based in MNA scores).

Fortified food may need to be offered more frequently, offering fortified snacks such as fortified soups or smoothies as well as meals.8 Alternatively, residents may need to be receiving prescribed nutritional supplements in addition to TMNF meals.

Interestingly, weight monitoring was poor, despite all residents in the study being on TMNF meals suggesting an acknowledgement of nutrition risk. Many residents were wheelchair, bed or chair bound, perhaps complicating regular weighing. Height records were also low, preventing a calculation of body mass index (BMI). Regular weights, recorded height or alte-rnative measures such as ulna length or knee height must be a priority for RACFs to allow prompt initiation of nutritional assessment and management.

Dysphagia-related medical aetiologies were common with over half diagnosed with dementia, half with an acquired or progressive neurological disease and two thirds without their own teeth. This is not surprising. Dysphagia is a symptom of pathology, not a diagnosis in its own right. Multiple medical diagnoses lead to multiple medications and dependence on others. All of these factors have been associated with dysphagia and aspiration pneumonia [20]. It is well recognised that polypharmacy can also increase the risk of malnutrition [21]. Dependence on feeding is a known risk factor for aspiration pneumonia [20]. Increased mealtime assistance has been shown to improve nutritional intake in RACFs [22] and staff responsible for feeding assistance have an important role to play in enhancing mealtime pleasure[7]. 8 Simple strategies such as ensuring a resident knows what their meal is: 'not given a menu so don't know what I'm eating'; 'I'm not sure which one ... it's a white colour.' 
Feeding staff training is essential for this complex population. The Universal Declaration of Human Rights and New Zealand Human Rights Act state that all people have the right to 'freedom of expression' and 'freedom from discrimination' irrespective of communication difficulties [23,24]. There are barriers to achieving this in the RACF setting where residents have cognitive and communication challenges. Yet, the majority of residents were able to offer opinion on mealtime preferences. Reassuringly, the majority of interviewees agreed that TMNF meals tasted good and the meal colour was appealing. Flavour fatigue is important to address in residents requiring monotextural foods. One of the ways to increase the aesthetic appeal of pureed meals is the use of food moulds. Food moulding was not mentioned in any of the RACFs in this study. Further kitchen staff training in maximising flavour and visual appeal of TMDs is needed.

In contrast, only $55 \%$ agreed that the aroma/smell of these meals was appealing. A number of factors are likely to impact on smell. Sensory acuity including taste, smell and texture perception diminish with age all of which can have an effect on food intake and nutritional status [25]. Declining olfactory function is highly likely in this cohort given their co-occurring cognitive and physical difficulties and polypharmacy [21,26,27].

Future research should address chemosensory alterations with ageing, perhaps exploring the addition of simulated flavours to food [ 2]. Meal temperature was important for residents. This can be an issue for those who take an increased amount of time to be fed due to swallowing difficulties or dependence on others. Sense of taste decreases with age [28]. This likely results in reduced appetite and satisfaction from eating as well as a preference for stronger tasting foods [29]. Residents frequently reported 'tasty' as a mealtime preference. Sweet tasty foods were important for many residents with 'sweet' rating highest on 'what food gives you the most pleasure?': 'I prefer the sweet stuff.' Puddings were rated higher than lunch and in-between meal items on overall satisfaction. Older adults are known to prefer sweet snack foods, served cold or frozen, and this was seen in this study 'I don't really enjoy the main meals' 'something sweet \& small'[30]. Regular feedback from residents would support menu design to reflect resident preferences.

Medical factors hindered mealtime enjoyment and choice: 'I'm blind so I can't see it'; 'I have sensitive bowels'; 'I miss carrots but I can't chew without teeth'; 'I love sweet things but I'm not allowed them'. While residential care living and medical conditions impact on autonomy to make one's own decisions, mealtime empowerment in older people may hold even greater merit. All efforts should be taken to allow residents to feel listened to.
Interestingly, there was a safety element in residents' mealtime satisfaction. While residents saw the taste of their food as being very important, equally important was the texture, with a desire to have food that was easy to eat. This highlights residents' awareness of choking and wish to be risk-free.

Having food of a guaranteed consistency may decrease anxiety around meal times. This may also reflect our established understanding of food processing changes with ageing. Compromised dentition, reduced bite force and masticatory function and reduced saliva flow [31,32] all impact on food choices in older people. In the absence of dysphagia, older people often choose easy-to-chew foods [31].

A recent systematic review highlighted the role of socialisation in mealtime culture in RACFs. Older people put high importance on opportunities for social connections at meal times. A quarter of respondents indicated they deemed eating with others to be of greatest importance: 'mum is a very social person \& loves sitting with other people', 'having family around gives me pleasure'. This response is supported by research which shows hospitalised older people consumed more when eating in communal environments $[32,33,34]$.

\section{Limitations and future directions}

There is an interesting skew in ethnicity data with the majority of residents either New Zealand European or European. This is a common pattern with a recently published survey finding only $2 \%$ of residents were Maori and 1\% Pacific Islander [35].

Much of the clinical data was reliant on accurate documentation. Level of dementia was not systematically quantified. Recording of residents' body height was not regularly completed on admission reducing the ability to complete BMI calculations. The scope of this project was limited to a documentation review and interview. Additional anthropometric measurements such as mid-calf circumference would add additional value.

The eligibility for this study was restricted to people receiving TMNFs. It would be interesting to explore the nutrition and mealtime satisfaction of a wider population of residents with and without swallowing and nutritional concerns. 
There are opportunities for more consumer involvement in the development of TMDs. A third of residents were on thickened fluids. Interviewers did not ask residents specifically about their satisfaction with drinks and no resident mentioned them. Mealtime observations were not conducted and plate waste was not measured. These would be interesting in future studies.

While it was anticipated carers and family members would need to assist with the interview process, it was not envisaged that almost all of the residents would be cognitively impaired, which made the interviewing process challenging and may have affected the accuracy of some of the consumer feedback. The use of skilled speech-language pathologists, trained in supported communication, is recommended in future studies. While residents were able to provide feedback with support, cognitive impairments prevented the interviewers from asking residents to provide comparisons between their commercial and in-house meals.

\section{Conclusions}

This is the first New Zealand study exploring texture-modified diet mealtime consumer satisfaction of older people with dysphagia living in long-term RACFs. Residents receiving commercially prepared TMNFs have complex medical issues, dysphagia and malnutrition risk. Regular weight monitoring is critical to ensure nutritional supports are maximised. Despite cognitive impairments, many residents were willing and able to offer suggestions for mealtime improvements. The development of sweet-tasting snack foods and the importance of residents knowing what the meal is that they are being offered is important. Food services should not discount the contributions of residents in menu planning for this vulnerable population.

\section{Funding Source:}

This project was funded by a Performance Based Research Fund from the School of Psychology, The University of Auckland.

\section{Ethics:}

This project gained national ethics approval from The University of Auckland Human Participants Ethics Committee (UAHPEC020683).

\section{Conflict of interest:}

The authors declare no conflict of interests.

\section{Reference}

1. Wham C, et al. Malnutrition risk of Older people across district health board community and residential care settings in New Zealand. Australas J Ageing. 2017; 36: 205-211.
2. Cereda E, et al. Nutritional Status in Older Persons according to health care setting: A systematic review and meta-analysis of prevalence data using MNA. Clin Nutr. 2016; 35:1282-1290.

3. Hudson $H$. The interdependency of proteinenergy malnutrition, ageing and dysphagia. Dysphagia. 2000; 15:31-38.

4. Keller $\mathrm{H}$, et al. Issues associated with the use of modifed texture foods. J Nutr Health Aging. 2012; 16:195-200.

5. Keller $\mathrm{HH}$, et al. Prevalence and determinants of Poor Food Intake of Residents living in long term care. J Am Med Dir Assoc. 2017; 18:941-941.

6. Vucea V, et al. Modified Texture Food Use is Associated with Malnutrition in Long Term Care: An Analysis of Making the Most of Mealtimes (M3) Project. J Nutr Health Aging. 2018; 22:916922.

7. Miles A, et al. Texture modified diets in aged care facilities: nutrition, swallow safety and mealtime experience early online. Australas J Ageing. 2019; 00:1-9.

8. Volkert D, et al. ESPEN guidelines on nutrition in dementia. Clin Nutr 2015; 34:1052-1073.

9. Beelen J, de Roos NM and de Groot LC. Protein enrichment of familiar foods as an innovative strategy to increase protein intake in institutionalized elderly. J Nutr Health Aging. 2017; 21:173-179.

10. Mills SR, et al. Can fortified foods and snacks Increase the energy and protein intake of hospitalised older patients? A systematic review. J Hum Nutr Diet. 2018; 31:379-389.

11. Ettinger L, Keller HH, Duizer LM. A Comparison of Liking of Pureed Food Between Two Groups of Older Adults. J Nutr Gerontol Geriatr. 2014; 33:198-209.

12. Von Elm E, et al. The Strengthening the Reporting of Observational Studies in Epidemiology (STROBE) statement: guidelines for reporting observational studies. J Clin Epidemiol. 2008; 16: e296-e230.

13. Belafsky P, et al. Validity and reliability of the Eating Assessment Tool (EAT-10). Ann Otol Rhinol Laryngol. 2008; 117:919-924.

14. Granic A, et al. Nutrition in the very old. Nutrients. 2018; 10:E269-E272.

15. Popman A, Richter M, Allen J, Wham C. High nutrition risk is associated with higher risk of dysphagia in advance age adults newly admitted to hospital. Nutr Diet. 2018; 75:52-58. 
16. MoH. Ministry of Health. 2013 NZ Health Survey. Wellington: Ministry of Health 2013. Date retrieved 1.3.19.

17. Eglseer D, et al. Dysphagia in Hospitalised Older Patients : associated factors and nutrient interventions. J Nutr Health Aging. 2018; 22:103-110.

18. Donini LM, et al. Mini nutritional assessment, malnutrition universal screening tool and nutrition risk screening tool for the nutritional evaluation of older nursing home residents. $\mathbf{J}$ Am Med Dir Assoc. 2016; 17:959.e11-8.

19. Dietitians Association of Australia. Evidence based practice guidelines for the nutritional management of malnutrition in adult patients across the continuum of care: Executive summary. Nutr Diet. 2009; 66:S1-S34.

20. Langmore SE, et al. Predictors of aspiration pneumonia: How important is dysphagia?. Dysphagia. 1998; 13:69-81.

21. Little MO. Updates in Nutrition and Polypharmacy. Curr Opin Clin Metab Care. 2018; 21:4-9.

22. Wright L, Cotter D and Hickson M. The effectiveness of targeted feeding assistance to improve the nutritional intake of elderly dysphagic patients in hospital. J Human Nutr Diet. 2008; 21:555-562.

23. New Zealand History. Universal Declaration of Human Rights and New Zealand Human Rights Act. Date retrieved 1.3.19.

24. Parliamentary Counsel Office. Human Rights Act 1993. Date retrieved 1.3.19.

25. Boesveld $S$, et al. The changing role of the senses in food choice and food intake across the life span. Food Qual Prefer. 2018; 68:80-89.

26. Toussaint N, et al. Loss of olfactory function and nutritional status in vital older adults and geriatric patients. Chem Sens. 2015; 40:197-203.

27. Schiffman SS. Influence of medications on taste and smell. World J Otolaryngol Head Neck Surg. 2018; 4:84-91.

28. Mojet J, Christ-Hazelhof E and Heidema J. Taste perception with age: pleasantness and its relationships with threshold sensitivity and supra-threshold intensity of five taste qualities. Food Qual Prefer. 2005; 16:413-423.

29. de Graaf C, van Staveren W and Burema J. Psychophysical and psychohedonic functions of four common food flavours in elderly subjects. Chem Sens. 1996; 21:293-302.

30. Okkels SL, et al. Acceptance of texture modified in between meals among older adults with dysphagia. Clin Nutr ESPEN. 2018; 25:126-132.

31. Hildebrandt GH, et al. Functional units, chewing, swallowing, and food avoidance among the elderly. J Prosthet Dent. 1997; 77:588-595.

32. Sakurai M, et al. Percentile curves for food acceptance response scores in assessing chewing functions in adults. Bull Tokyo Dent Coll. 2005; 46:123-134.
33. Markovski K, et al. Does eating environment have an impact on the protein and energy intake in the hospitalised elderly? Nutr Diet. 2017; 74:224-228.

34. Charras K and Fremontier M. Sharing meals with institutionalized people with dementia: a natural experiment. J Gerontol Soc Work. 2010; 53:436438.

35. Kiata L, Kerse N and Dixon R. Residential care workers and residents: the New Zealand story. $\mathrm{N}$ Z Med J. 2005; 118:1-11. 